\title{
Assessment of Co-Creativity in the Process of Game Design
}

\author{
Margarida Romero ${ }^{1}$, Sylvester Arnab $^{2}$, Cindy De Smet ${ }^{1}$, Fitri Mohamad ${ }^{3}$, Jacey-Lynn Minoi ${ }^{3}$ \\ and L. Morini \\ ${ }^{1}$ Laboratoire d'Innovation et Numérique pour l'Education, Université Côte d'Azur, Nice, France \\ ${ }^{2}$ Coventry University, Coventry, UK \\ ${ }^{3}$ Social Informatics and Technological Innovations, University Malaysia Sarawak, Malaysia \\ Margarida.Romero@unice.fr \\ S.Arnab@coventry.ac.uk \\ cindy.de-smet@univ-cotedazur.fr \\ mfitri@unimas.my \\ jacey@unimas.my \\ ac2009@coventry.ac.uk \\ DOI: 10.34190/JEL.17.3.003
}

Abstract: We consider game design as a sociocultural and knowledge modelling activity, engaging participants in the design of a scenario and a game universe based on a real or imaginary socio-historical context, where characters can introduce life narratives and interaction that display either known social realities or entirely new ones. In this research, participants of the co-creation activity are Malaysian students who were working in groups to design game-based learning resources for rural school children. After the co-creativity activity, the students were invited to answer the co-creativity scale, an adapted version of the Assessment Scale of Creative Collaboration (ASCC), combining both the co-creativity factors and learners' experiences on their interests, and difficulties they faced during the co-creativity process. The preliminary results showed a high diversity on the participants' attitudes towards collaboration, especially related to their preferences towards individual or collaborative work.

Keywords: game-based learning, game design, creativity, co-creativity process, collaboration

\section{Creative education approaches for a critical and creative society}

Nowadays, creativity is recognised as a critical competence in an increasingly volatile world, resulting in higher levels of uncertainty, complexity and ambiguity (VUCA, Bennis and Nanus, 1985) compared to prior centuries of the pre-industrial and industrial periods. Despite a growing corpus of theoretical and empirical studies on creativity in the last decades (Albert and Runco, 1999; Ryhammar and Brolin, 1999), creativity is a natural characteristic of humanity. Creativity is described as the ability to develop processes or achievements that are both new, relevant, and valuable while adjusting to the context in which they occur (Long, 2014; Runco, 2013, p. 201; Runco and Jaeger, 2012). Authors like Osborne (2003) criticise the fact that creativity has become a moral and socioeconomic imperative nowadays, while other studies highlight the socio-economic differences that are emerging between the "creative classes" and those who do routine jobs. Creative classes develop occupations where creativity is a determining factor; while routine workers are facing growing insecurity in urban environments (Florida, 2014). However, creativity is also defended among humanist approaches aiming to develop agency (Engeström and Sannino, 2013) or to engage citizens in co-creative solutions (Barma, Romero, \& Deslandes, 2017). Moreover, creativity has been highlighted as one of the key skills for employment expected in 2020 (World Economic Forum, 2016). In education, creative pedagogies encompass different perspectives, including creative teaching practices and learners' creative skills (Capron-Puozzo, 2014; Kiili et al., 2012).

\subsection{Co-creativity as a person-team-situation interaction}

Creativity is considered contextual and judgmental by a reference group (Romero and Barberà, 2014). The contextual nature of creativity is problematic in terms of its conceptual approach and the difficulties encountered when assessing it as a generic skill (Burnard, 2006; Puozzo, 2016). Moreover, the contextual and situation-specific nature of creativity is defended by Woodman and colleagues (1993) within an interactionist model of creative behaviour, "that incorporates elements of personality, cognitive, and social psychology explanations of creativity. In the model, creative behaviour is viewed as a complex person-situation interaction" (Woodman and Schoenfeldt, 1990, p. 279), which engages a complex interaction between the person and the situation. In a co-creative activity, we assume that interaction is not only developed within the person and the situation, but as a person-team-situation interaction, which requires a multilevel approach to 
analyse creativity. To identify the multilevel nature of co-creativity within the game design process, we consider co-creativity as an element within the broader creative pedagogy framework (Figure 1).

\section{Creative pedagogy}

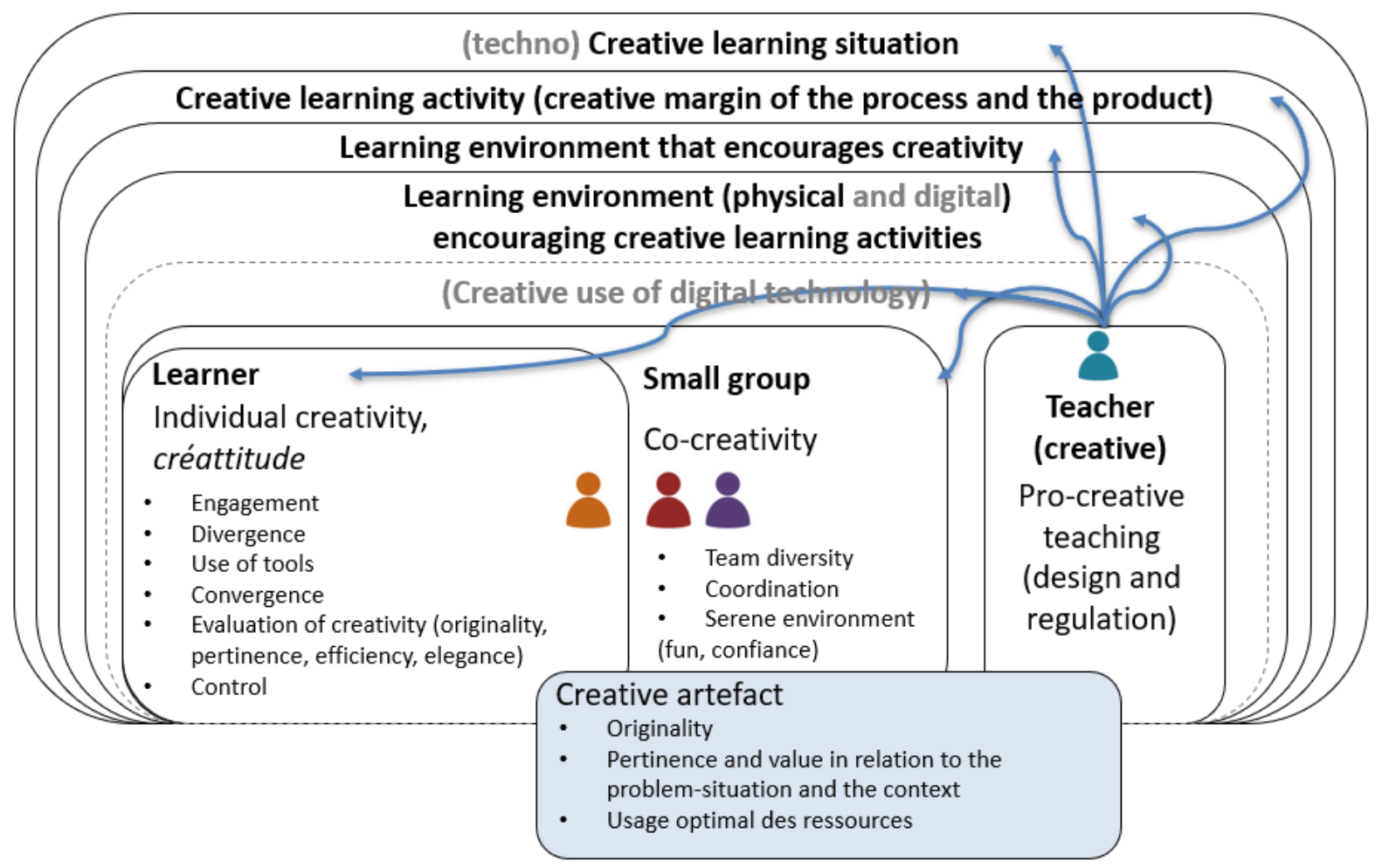

Figure 1: Creative pedagogy framework

The multiple levels of the creative pedagogy framework shown in Figure 1 should be considered in its entirety. Within this study, we focus on the teamwork level and the co-creative self-assessment developed by the participants. Within the creative approach of the participants, we consider not only the situation, and the way teams overcome their difficulties during the co-design process but also on their attitudes towards creative activity. Within the set of creative attitudes related to creativity, we will focus on tolerance to ambiguity (DeRoma et al., 2003) as "the tendency to perceive ambiguous situations as desirable" (Budner, 1962, p. 28). In creative activities in which learners are not supplied with all the required information leading to a solution, described by Simon (1973) as ill-defined problems. Between well-structured and ill-defined activities, there is a broad spectrum of activities providing different degrees of creative freedom in the process and the outcomes of the activity. We can consider the degrees of creative freedom to be the number of possibilities learners have to develop the activity process and the outcome process in a different, but still valuable, way. The degrees of creative freedom can be regulated by the teacher in introducing constraints reducing or expanding the degrees of creative freedom.

The appreciation of the degrees of creative freedom experienced by the learners could depend on their tolerance to ambiguity, but also contextual aspects as the cognitive load level or the collaborative settings of the activity. Activities with a high degree of creative freedom could be inconvenient for students preferring well-defined activities, providing them with a clear structure and guidance. In these cases, some learners show their rejection of highly creative activities and describe to prefer well-structured activities (Cliburn et al., 2010).

\section{Designing games for learning}

Playing games could support certain types of learning, but participants can also learn from designing games (Arnab et al., 2017; Cucinelli et al., 2016). When creating games, the participants shift from a consumer approach of digital technologies towards a co-creative approach transitioning from consuming technology to the co-creating through technology has been possible, thanks to two essential levers: the technological evolution and the spread of the participatory approach in education. Firstly, the evolution of technologies resulted in the popularization of game engine platforms, and the emergence of visual programming platforms 
such as Scratch, but also led to the creation of basic arcade-style games, indie-style games or even patternbased games, in which the participant can customize an existing game pattern (Richard \& Kafai, 2015; Woods, 2015). Secondly, in research and media studies, there has been a tendency to consider the participant as a creative agent within a shared collective creation process, rather than as an end-user who will be engaged as an interactive consumer of a professionally-developed product.

\section{Malaysian game design workshop}

As part of the CreativeCulture project (http://mycapsule.my), a four-day workshop was held at the Learning Sciences Studio, situated at the Faculty of Cognitive Sciences and Human Development UNIMAS, Malaysia.

Eighteen Masters students ( $n=9$ were trained teachers) in Learning Sciences, were enrolled in a course on Computer-Supported Collaborative Learning $(\mathrm{CSCL})$ and were engaged in a Design Thinking workshop within their CSCL course. The workshop aimed to provide an opportunity to co-create game-based learning resources in the fields of English as Foreign Language (EFL) and Sciences Technology Engineering and Mathematics (STEM). None of the Masters' students has used a gamification approach in learning. Playful-and-gameful approaches to education inspire the Design Thinking workshop. The main contents of the workshop have been developed by the GameChangers initiative (Arnab et al. 2017) and were adapted to the Learning Sciences field.

In the adaptation process, the focus was placed on the process of learning, and strategies to determine how gamification elements can be integrated into learning.

The Design Thinking workshop initiated four months' worth of work, as the Masters' students used the knowledge and skills they learned in the workshop to conduct Gamification of Learning sessions at two rural schools. While developing the EFL and STEM game-based learning resources, the students also needed to incorporate the use of technology into the gameplay, to fulfil the requirements of the CSCL course.

Designing game-based learning resources for the rural schools posed a challenge for the master's students; a majority of them were only familiar with urban and semi-urban schools. From the start, they felt less confident with subcultures of ethnic groups in both locations. At these two schools, the school subculture was dominantly identified by the majority ethnic Malay; in the case of the master's students, they mainly have had experience in learning and teaching in majority ethnic Chinese, Iban and Bidayuh, where school subcultures were valued differently.

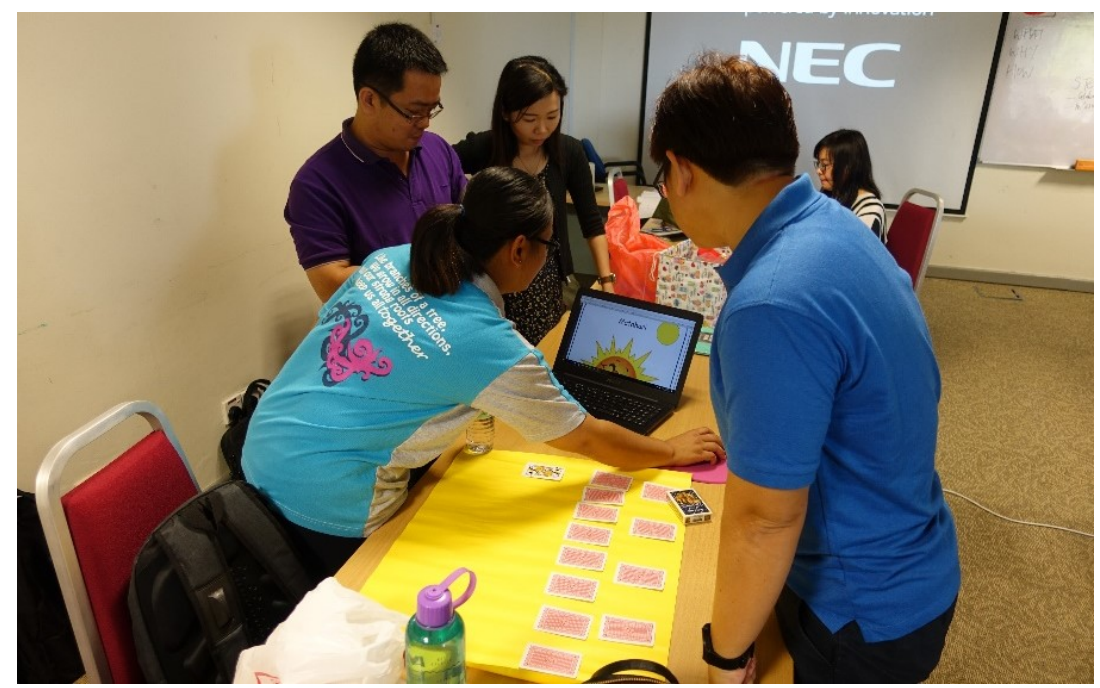

Figure 2: Malaysian students during the co-creation process

\section{Methodology}

In the workshop, the participants went through a three-stage process: the co-creation phase, the piloting phase and the reflection phase at the end. We describe below each the stages and their different steps. 


\subsection{Stage 1: Co-creation of game-based learning resources via the GameChanger's design thinking process}

The design process, based on the GameChanger's approach, aims to make game-based design thinking more accessible to anyone with a different level in game playing. Inspired by the engaging nature of play and gameplay as a tool for learning (Fabricatore, 2007), the workshop required the participants to emphasise on designing playful experiences suited for the target audience (primary-level STEM education). Participants were divided into six groups. Each team was informed on the type of game-based resources (digital or analogue) that could be co-created to facilitate engaging learning experiences. At the end of the workshop, the teams developed six game-based learning resources. Five steps were utilised to create game-based learning resources. These five steps were coherent with the design thinking approach (Owen, 2007) of the participatory design (Cucinelli et al., 2016) in which the participants go through different phases for iteratively developing the game. By working on iterative cycles of improvement, the participants can engage in different ideas and support their co-creativity.

Stage 1 - Step 1: Understand the needs, context and audience. What are the key challenges you wish to address? What are the objectives/aims/goals? Who are your stakeholders? And in what context would your solution/intervention be implemented?

Stage 1 - Step 2: Get inspired by existing play and gameplay. What play and game activities do you like most? Can you list them out? What is the core mechanics of those activities? Are there any particular game and play strategies that you can think of? Map the different mechanics and use them as inspirations for the next step.

Stage 1 - Step 3: Map the needs and goals of the mechanics and strategy. How would you engage the stakeholders? Will specific strategies promote the aims and objectives you set out? What play and game activities would develop specific actions, attitudes and/or behaviour?

Stage 1 - Step 4: Design your game. Design and develop your strategy/solution/product/experiences that will address the challenges, achieve the goals and engage the stakeholders in the context that you set out in the beginning. Test your game.

Stage 1 - Step 5: Pitch your game. Share your game plan and get feedback from your peers.

\subsection{Stage 2: Piloting of the resources developed in schools}

For the CreativeCulture project, two rural schools had been pre-selected for the training. The pilot activities were also part of the iterative testing process that the Masters' students managed. The selected schools shared similar demographic characteristics - they were coastal fishing villages, predominantly ethnic Malay, and of a low socioeconomic income group. Four gamification sessions were held at the two schools. In the first session, Gamification in Learning for the teaching of STEM subjects was introduced to the school teachers. The output of the first session was a selection of learning contents which were identified as "problematic" by the school teachers. The contents were further developed into learning games by the Masters' students. The subsequent sessions were conducted with the primary school pupils, in which they engaged in games developed by the Master's students and their teachers through a co-creative process. Within the CreativeCulture project, teachers and pupils were engaged in the co-creative design, development and playing moments of the project.

\subsection{Stage 3: Reflection from the teachers via the co-creativity questionnaires (Data Collection)}

During this stage, the participants filled out a questionnaire based on the co-creativity scale, an adapted version of the Assessment Scale of Creative Collaboration (Romero and Barberà, 2015; Wishart and Eagle, 2014). This new version contains a five-level scale, combining both the co-creativity factors and the participants' reflections on their preferences, and the difficulties faced during the co-creativity process. The participants' observations were reported through open questions focusing on the positive and negative aspects of the game co-creation process, and the main difficulties faced during the project and the strategies developed to overcome them. 


\section{Results}

We analysed the answers, focusing on the participants' perceived levels towards tolerance of ambiguity, which we linked to their preference to have either very guided instructions or ill-defined tasks. Based on these preferences, we differentiated between participants with a low level of tolerance to ambiguity ( $n=10$ and including answers from 1 to 3 ) and participants with a higher level of tolerance to ambiguity ( $n=4$ and including answers from 4 to 5). Four participants did not answer the co-creativity scale.

\subsection{Co-creativity self-assessment according to the tolerance of ambiguity}

Participants with a low level of tolerance to ambiguity tend to assess their game design more favourably in terms of efficiency, originality and value. Those with high levels of tolerance towards ambiguity are found to be more critical when judging their co-creative outcome after the co-creation of the game.

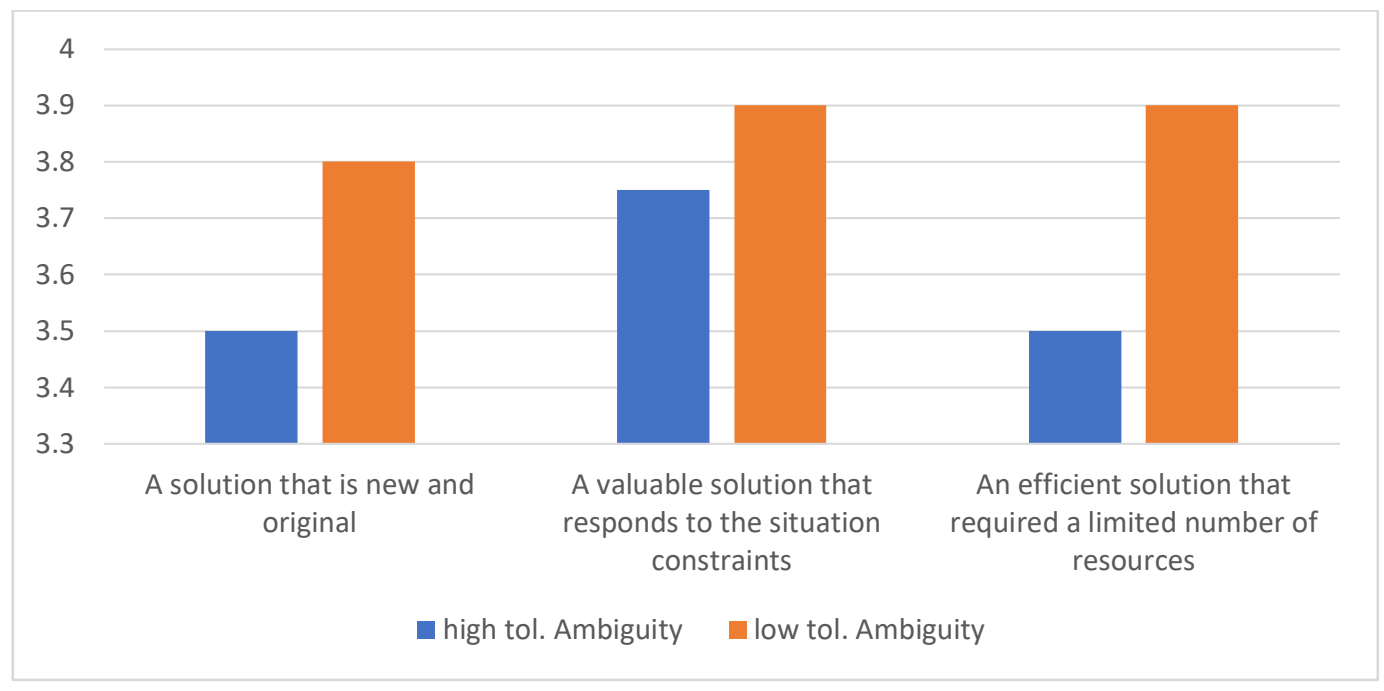

Figure 3: Co-creativity self-assessment according to the tolerance of ambiguity

\subsection{Task preferences according to the tolerance of ambiguity}

Participants with low levels of tolerance to ambiguity paid more attention to detail, took pride in work well done and preferred more straightforward tasks requiring little abstraction.

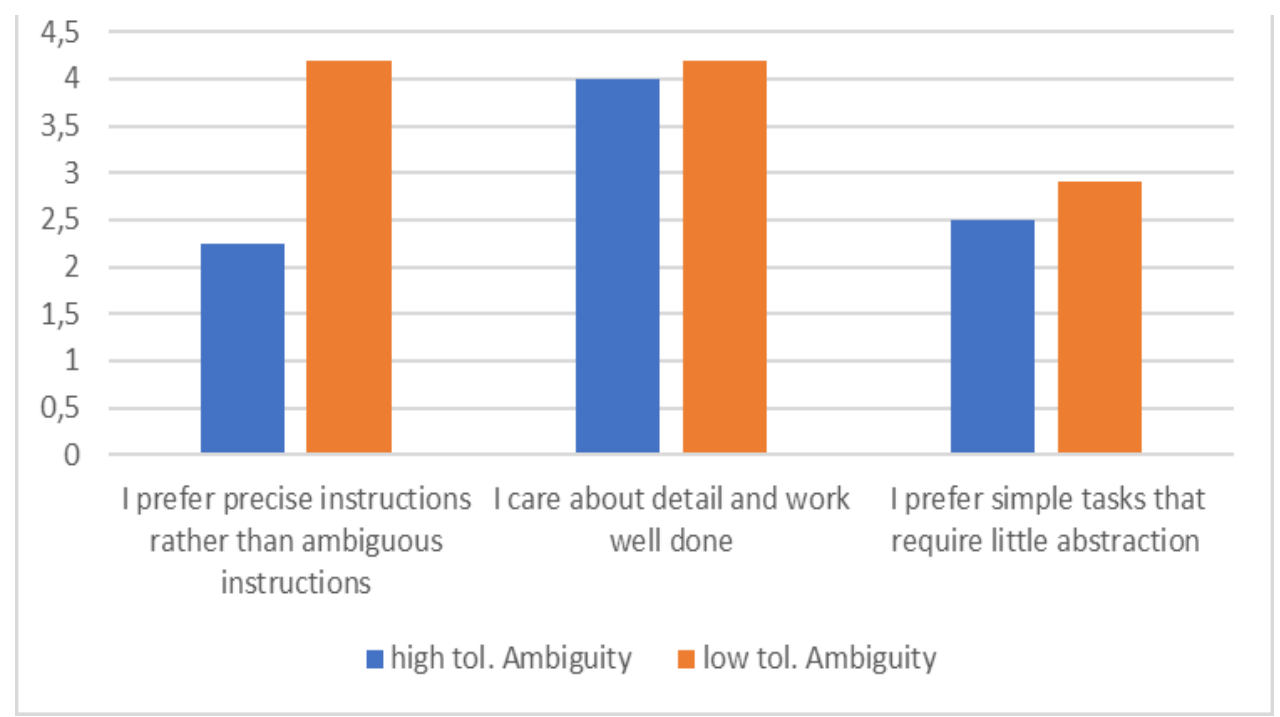

Figure 4: Creative orientation of the CreativeCulture learners

\subsection{Attitudes towards teamwork and errors according to the tolerance of ambiguity}


Participants with low tolerance to ambiguity, are more prone to help others, tend to accept their errors and those of others, but also prefer individual work above teamwork. When facing difficulties, they are more willing to intervene and to act.

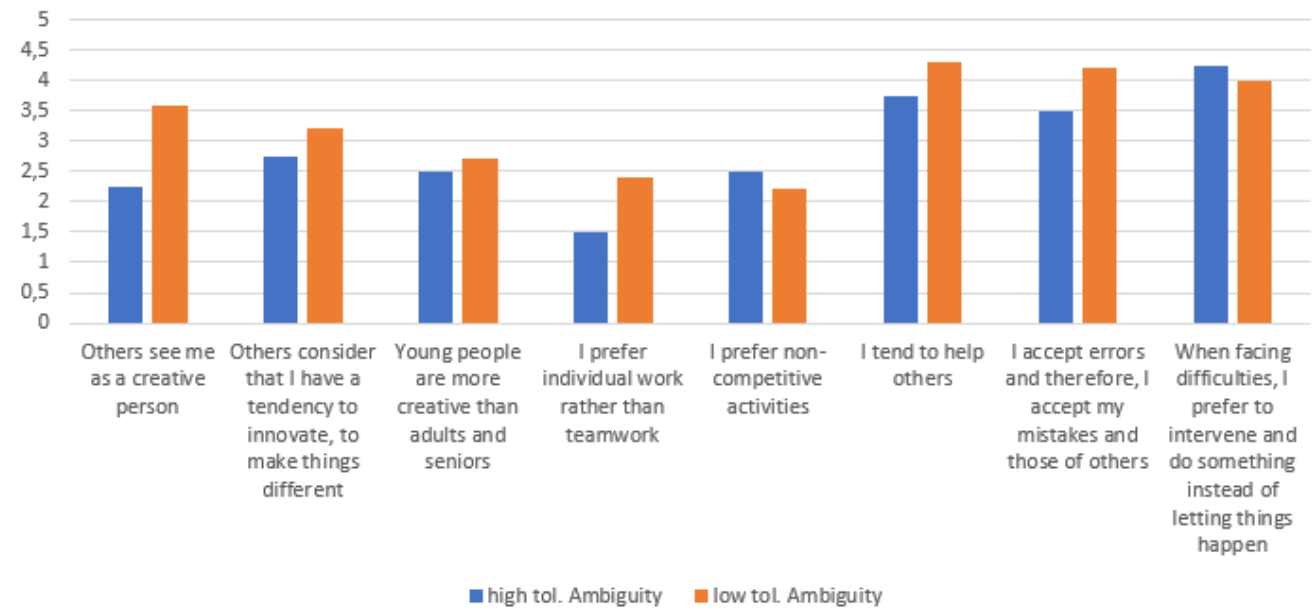

Figure 5: Attitudes towards teamwork and errors according to the tolerance of ambiguity

\section{4 "What were the main positive aspects of the project?"}

The main positive aspects of the project, as highlighted by participants were related to the cooperation within their team. For example, one of the participants mentioned that the main positive aspects of the CreativeCulture project were that "they were able to work together towards a common goal they invested in", while another student appreciated "to collaborate among themselves despite their different backgrounds and ideas". The statement reflects the diversity of ideas experienced during the initial stages of the co-creative process. Another student highlighted on the convergence process after the initial divergent stage: "the group itself became closer as they carried [on with] the project. [Particpants] were able to understand each other better and therefore, conducted the project wonderfully". Participants also thought "it was possible to obtain new and creative ideas from their team-mates" and agreed to value the diversity of ideas shared within the team. During the co-creation process, they were aware "they could collaborate and help the pupils to learn by gamifying".

Moreover, they also understood that teamwork produces better outcomes than individual work. For them, it was possible "to learn from others perspective". Participants also highlighted that "the project inspired the teachers' ideas to (re?)design their teaching approach".

Co-creative attitudes were found to be necessary during the co-creation, and the Masters' students also highlighted the trust required from team members and the "creative and fun elements experienced when developing games". They remarked that a "fun, creative and trustful atmosphere was necessary during the cocreation process".

\subsection{What were the main negative aspects of the project?}

Negative comments were made on the poor organisation (of what?) and a lack of collaboration and sharing (of what?) that led to tensions and an imbalance (of what) in the student teams. Participants found that "the time to prepare for the project was insufficient". Furthermore "some of the members from other team became a little too competitive, even though both teams were supposed to work together". Another problem raised was that "both teams involved in this project faced conflicts due to "different opinions" and "some people refused to discuss other ideas". In this case, a participant highlighted that "communication breakdowns led to frustration and disappointment". It led to "miscommunication, unfair distribution of work between team members and the other team to organize a collaborative activity".

\subsection{What were the main difficulties encountered during the creative project?}

The main difficulties encountered are based on "limited resources and expertise to build products and services" in order "where all members agreed on". A difficulty mentioned was how "they could produce a 
relevant game"? It is hard to "create games suitable for learning, especially for primary students", and "how ideas could be transformed into games". Another challenge is "to come to an agreement for the solution used within the project, and to figure out the motives of others". Also, "the learners were "constantly chasing time, and communications problems make it harder". While having fun and having problems could be perceived as incompatible, we understand the possibility to have fun while fighting through the "effortful pleasure" or "pleasurable effort" concept of Rosenbaum (1990). Furthermore, during the actual roll-out on the site at the rural schools, "unexpected weather conditions blocked the entrance of the project site".

\subsection{How did you overcome them, or do you plan to overcome them?}

To overcome difficulties, participants described how they "voted" or "discussed within the team". In other cases, they asked the school teacher for help (in their words, they "interviewed the teacher") or "confronted the [team] member even though he is older". The participants declared they had the intention "to have more open discussions and to ironing out issues". Also, they added all members did their best to read through the journal articles related to gamification and to "figure out the best way to solve the problems". The participants explained they did their best to overcome the game challenges by simulating the activity beforehand. They planned for contingency for instances where specific problems would occur. They also presented the ideas about the games they developed, so they were able to gauge what was learned while playing the games.

Another participant confessed how he initially faced difficulty with solving the problems encountered but was soon able to find out "every problem has its solution". Participants also took the initiative to "visit an institution to get inspired", which helped them to commence with gamification for their project.

\section{Discussion}

Co-creativity is key to encouraging collective knowledge, experiences, interests and expertise, and to be exploited towards larger projects that could potentially lead to creative solutions impacting the significant challenges currently faced in society (global warming, climate change and so forth.). Designing and creating games as an activity on the edge of the diverse fields of Art, Design, Science, Computation and Engineering, can be a fertile ground to cultivate such competencies through multi-disciplinary collaboration, and by providing a playful (engaging), creative and innovative space for people to meet and learn how to cooperate fruitfully. The CreativeCulture project provides a platform for those who are not used to engage in game design to co-create gameful solutions for teaching and learning of STEM topics, focusing on the rural schools in Malaysia as the target audience for these game-based learning resources.

The co-creation experience with the Masters' students confirmed our assumption that pedagogical and content knowledge are challenged when designing games for schools with subcultures that are unfamiliar to the participants. It also shows the importance to situate the learning cultures of schools, and to make the learning experience aligned to the local teaching practices. Co-creativity also enabled the students to interact in this project, which helped them to create their game-based learning modules. However, further work is required to understand the existing assumptions, motivation and determination to learn and teach in various school settings. Eventually, co-creativity requires a positive team climate, which is mainly related to the error and ambiguity tolerance observed through this activity. The team climate and attitudes are one of the most important lessons learnt through the co-creation experience with the Malaysian Masters' students, and with the other teams engaged in co-creativity activities within the activities, we developed in the last years (Cucinelli et al., 2016; Romero et al., 2016). Further work is required to allow more time for the students and teachers to co-create game-based resources to meet the needs of different schools, which will include repurposing existing traditional games that are more relatable to the community.

\section{Acknowledgements}

The work was partly funded under the CreativeCulture project by Newton AHRC-MoHE (UK SEA-NUOF JPTS(BPKI)2000/04/07/05(33) fund.

\section{References}

Albert, R.S. and Runco, M.A. (1999), "A history of research on creativity", Handbook of Creativity, Vol. 2, pp. 16-31. Arnab, S., Morini, L., Green, K., Masters, A. and Bellamy-Woods, T. (2017), “We are the Game Changers: An Open Gaming Literacy Programme", International Journal of Game-Based Learning (IJGBL), Vol. 7 No. 3, pp. 51-62.

Bennis, W. and Nanus, B. (1985), "The strategies for taking charge", Leaders, New York: Harper. Row. Budner, S. (1962), "Intolerance of ambiguity as a personality variable", Journal of Personality, Vol. 30 No. 1, pp. 29-50. 
Burnard, P. (2006), "Reflecting on the creativity agenda in education", Cambridge Journal of Education, Vol. 36 No. 3, pp. 313-318.

Capron-Puozzo, I. (2014), “Pour une pédagogie de la créativité en classe de langue: réflexion théorique et pratique sur la triade créativité, émotion, cognition”, Voix Plurielles, Vol. 11 No. 1, pp. 101-111.

Cliburn, D.C., Miller, S.M. and Bowring, E. (2010), "Student preferences between open-ended and structured game assignments in CS1", 2010 IEEE Frontiers in Education Conference (FIE), IEEE, pp. F2H-1.

Cucinelli, G., Davidson, A.-L. and Romero, M. (2016), "Participatory game design in intergenerational contexts: Co-designing digital games for intergenerational learning using Scratch", Montréal, Québec, Canada, 22 October.

DeRoma, V.M., Martin, K.M. and Kessler, M.L. (2003), "The relationship between tolerance for ambiguity and need for course structure", Journal of Instructional Psychology, Vol. 30 No. 2, p. 104.

Engeström, Y. and Sannino, A. (2013), "La volition et l'agentivité transformatrice: perspective théorique de l'activité", Revue Internationale Du CRIRES: Innover Dans La Tradition de Vygotsky, Vol. 1 No. 1, pp. 4-19.

Fabricatore, C. (2007), "Gameplay and game mechanics design: a key to quality in videogames", Proceedings of OECD-CERI Expert Meeting on Videogames and Education.

Florida, R. (2014), The Rise of the Creative Class-Revisited: Revised and Expanded, Basic Books.

Kiili, K., Kiili, C., Ott, M. and Jönkkäri, T. (2012), "Towards creative pedagogy: Empowering students to develop games", 6th European Conference on Games Based Learning, Academic Conferences Limited, p. 250.

Long, H. (2014), "More than appropriateness and novelty: Judges' criteria of assessing creative products in science tasks", Thinking Skills and Creativity, Vol. 13, pp. 183-194.

Osborne, T. (2003), “Against 'creativity': a philistine rant", Economy and Society, Vol. 32 No. 4, pp. 507-525.

Owen, C. (2007), "Design Thinking: Notes on its nature and use", Design Research Quarterly, Vol. 2 No. 1, pp. 16-27.

Puozzo, I.C. (2016), La Créativité En Éducation et Formation: Perspectives Théoriques et Pratiques, De Boeck Superieur.

Romero, M. and Barberà, E. (2014), "Computer-Based Creative Collaboration in Online Learning", New Horizons in WebBased Learning, Springer, pp. 330-336.

Romero, M. and Barberà, E. (2015), "Creative collaboration in online Computer-Supported Collaborative Learning", presented at the European Distance and E-Learning Network 2015, EDEN, Barcelona, pp. 593-598.

Romero, M., Sawchuk, K., Blat, J., Sayago, S. and Ouellet, H. (2016), Game-Based Learning across the Lifespan, Springer Science+Business Media, New York, NY.

Rosenbaum, R. (1990), "Strategic psychotherapy", Handbook of the Brief Psychotherapies, Springer, pp. 351-403.

Runco, M.A. (2013), Divergent Thinking and Creative Potential, Hampton Press.

Runco, M.A. and Jaeger, G.J. (2012), "The standard definition of creativity", Creativity Research Journal, Vol. 24 No. 1, pp. 92-96.

Ryhammar, L. and Brolin, C. (1999), "Creativity Research: historical considerations and main lines of development", Scandinavian Journal of Educational Research, Vol. 43 No. 3, pp. 259-273.

Wishart, J. and Eagle, S. (2014), "The Development of a Scale to Assess Creative Collaboration via Online Tools", New Horizons in Web-Based Learning, Springer, pp. 320-329.

Woodman, R.W., Sawyer, J.E. and Griffin, R.W. (1993), "Toward a theory of organizational creativity", Academy of Management Review, Vol. 18 No. 2, pp. 293-321.

Woodman, R.W. and Schoenfeldt, L.F. (1990), "An interactionist model of creative behavior", The Journal of Creative Behavior, Vol. 24 No. 4, pp. 279-290. 